\title{
ON WHITEHEAD'S SECOND LEMMA FOR LIE ALGEBRAS
}

\author{
WILLIAM T. FLETCHER \\ Department of Mathematics \\ North Carolina Central University \\ Durham, North Carolina 27707 \\ (Received December 4, 1980 and in Revised form September 15, 1981)
}

ABSTRACT. A proof of Whitehead's second lemma which is independent of the first Whitehead lemma is given.

KEY WOROS AND PHRASES. Whitehead's second lemma, Casimir operator, Levi's theorem. 1980 MATHEMATICS SUBJECT CLASSIFICATION CODE. $17 B 99$.

\section{INTRODUCTION.}

THE SECOND WHITEHEAD LEMMA FOR LIE ALBEBRAS. Let L be a finite-dimensional semi-simple Lie algebra of characteristic 0, M a finite-dimensional L-module and $(\mathrm{x}, \mathrm{y}) \rightarrow \mathrm{g}(\mathrm{x}, \mathrm{y})$ a bilinear mapping of $\mathrm{L} \times \mathrm{L}$ into $\mathrm{M}$ such that

$$
\begin{gathered}
g(x, x)=0, \\
g([x y], z)+g(x, y) z+g([y z], x)+g(y, z) x+g([z x], y)+g(z, x) y=0 .(1.2)
\end{gathered}
$$

Then there exists a linear mapping $x \rightarrow x^{\alpha}$ of $L$ into $M$ such that

$$
g(x, y)=x^{\alpha} y-y^{\alpha} x-[x y]^{\alpha} \text {. }
$$

The standard proof of the second Whitehead lemma for Lie algebras of characteristic 0 [1, p. 89] considers the three cases: $\Gamma$, the Casimir operator, is nonsingular; $\Gamma$ is nilpotent; and $\Gamma$ is neither non-singular nor nilpotent and; in the case where $\Gamma$ is nilpotent, the proof depends on the first Whitehead lemma. The purpose of this note is to give a simplification of the proof for the case $\Gamma$ is nilpotent which is independent of the first Whitehead lemma. This, of course, will simplify the proof of the Levi theorem which is one of the main uses of the lemma. 
For our purposes here we will need the following lemma, the proof of which follows easily from Theorem 2 of [2] and the properties of the complementary basis.

LEMMA 1. If $\mathrm{A}$ is a finite-dimensional Lie algebra which has non-degenerate Killing form with basis $\left(e_{1}, e_{2}, \ldots ., e_{n}\right)$ and complementary basis $\left(e_{1}^{\prime}, e_{2}^{\prime}, . .\right.$. $\left.e_{n}^{\prime}\right)$, then for a bilinear mapping $f(x, y)$ of $A \times A$ into $A$

$$
\sum_{k} f\left(\left[e_{k}^{\prime} x\right],\left[y e_{k}\right]\right)=\sum_{k} f\left(\left[e_{k} x\right],\left[y e_{k}^{\prime}\right]\right) \text {. }
$$

\section{PROOF OF THE MAIN RESULT.}

We introduce the following notation: $R$ is the kernel of the representation of $L$ determined by $M, L_{1}$ is an ideal such that $L=R \bullet L_{1},\left(u_{i}\right)$ and $\left(u_{i}^{\prime}\right)$; $i=1,2, \ldots ., m$ are dual bases of $L_{1}$ relative to the trace form of the given representation, $\Gamma$ is the Casimir operator determined by the dual bases and is the mapping $x \rightarrow \sum_{i}\left(x u_{i}\right) u_{i}^{\prime}$ in $M$. Suppose that $\Gamma$ is nilpotent, then $m=0, R=L$, and the representation determined by $M$ is the zero representation. Then (1.2) reduces to:

$$
g([x y], z)+g([y z], x)+g([z x], y)=0
$$

Let $\left(e_{i}\right)$ and $\left(e_{i}^{\prime}\right) ; i=1,2, \ldots$, n be a dual basis for $L$ and in (2.1) set $z=\left[\right.$ we $\left._{i}\right], y=e_{i}^{\prime}$ and sum over $i$ to get

$$
\sum_{i}\left\{g\left(\left[x e_{i}^{j}\right],\left[w e_{i}\right]\right)+g\left(\left[e_{i}^{\prime}\left[w e_{i}\right]\right], x\right)+g\left(\left[e_{i} x\right],\left[e_{i}^{i}\right]\right)\right\}=0 \text {. }
$$

Since $L$ is non-degenerate in the sense of [2], Theorem 2 of [2] implies that $\sum_{i}\left[e_{i}^{\prime}\left[w_{i}\right]\right]=-w$, and $(2.2)$ reduces to

$$
\sum_{i}\left\{g\left(\left[x e_{i}^{i}\right],\left[w e_{i}\right]\right)-g(w, x)+g\left(\left[e_{i} x\right],\left[e_{i}^{\prime} w\right]\right)\right\}=0 \text {. }
$$

We can verify that

$$
\begin{aligned}
\sum_{i} g\left(\left[e_{i}[w x]\right], e_{i}^{\prime}\right) & =-\sum_{i}\left\{g\left(\left[w\left[x_{i}\right]\right], e_{i}^{\prime}\right)+g\left(\left[x\left[e_{i} w\right]\right], e_{i}^{\prime}\right)\right\} \\
& =-\sum_{i}\left\{g\left(\left[x e_{i}^{\prime}\right],\left[w e_{i}\right]\right)+g\left(\left[x_{i}\right],\left[w e_{i}^{\prime}\right]\right)\right\} \\
& =-2 \sum_{i} g\left(\left[x_{i}^{\prime}\right],\left[w e_{i}\right]\right), \text { by Lemma } 1 .
\end{aligned}
$$


Now if we substitute the above result in (2.3), we get

$$
-g(w, x)-\sum_{i} g\left(\left[e_{i}[w x]\right], e_{i}^{\prime}\right)=0 .
$$

Thus, we obtain a linear mapping $\alpha$ of $L$ into $M$ such that

$$
g(w, x)=-[w x]^{\alpha}=-\sum_{i} g\left(\left[e_{i}[w x]\right], e_{i}^{\prime}\right) \text {. }
$$

\section{REFERENCES}

1. JACOBSON, N. Lie Algebras, Interscience Pub1., No. 10, New York, 1962.

2. CAMPBELL, H.E. On the Casimir Operator, Pacific J. of Math. 7, No. 3 (1957), 1325 - 1331. 


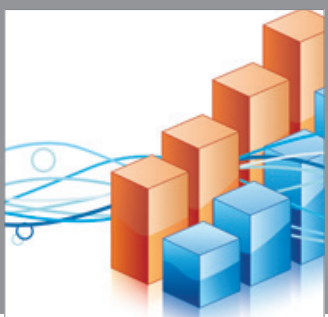

Advances in

Operations Research

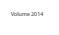

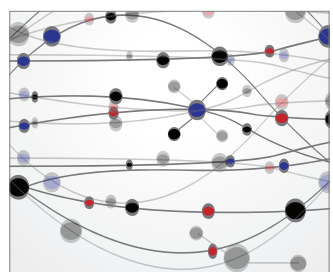

\section{The Scientific} World Journal
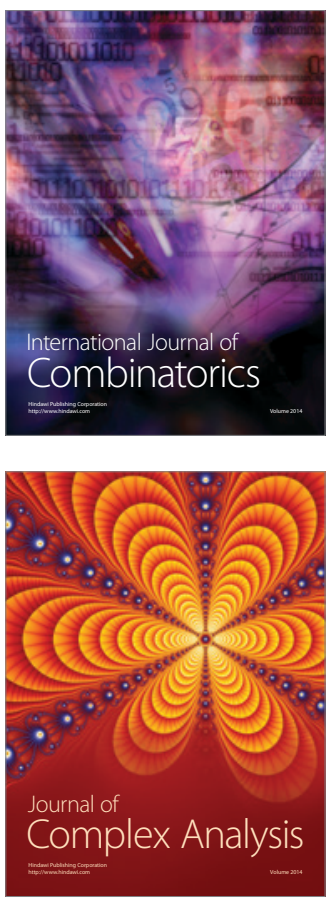

International Journal of

Mathematics and

Mathematical

Sciences
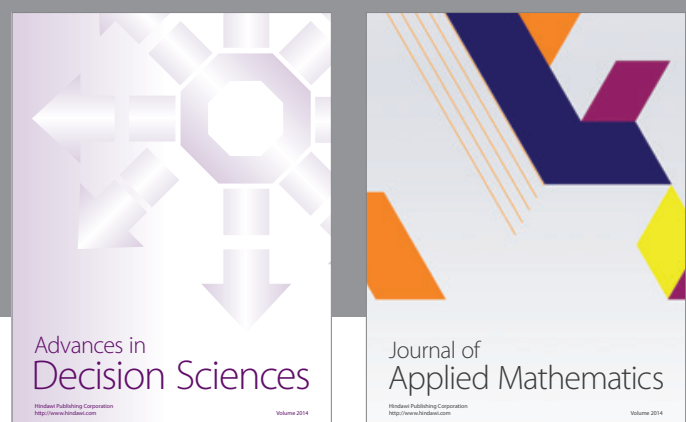

Journal of

Applied Mathematics
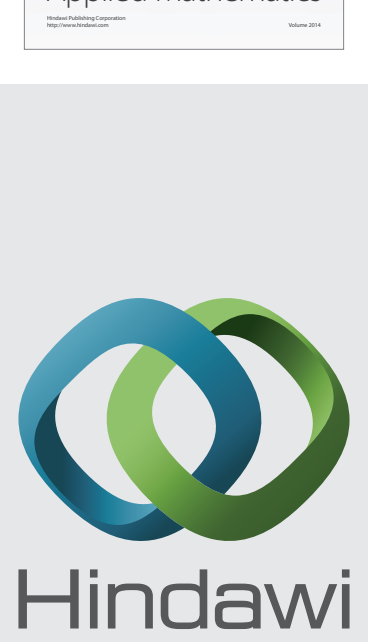

Submit your manuscripts at http://www.hindawi.com
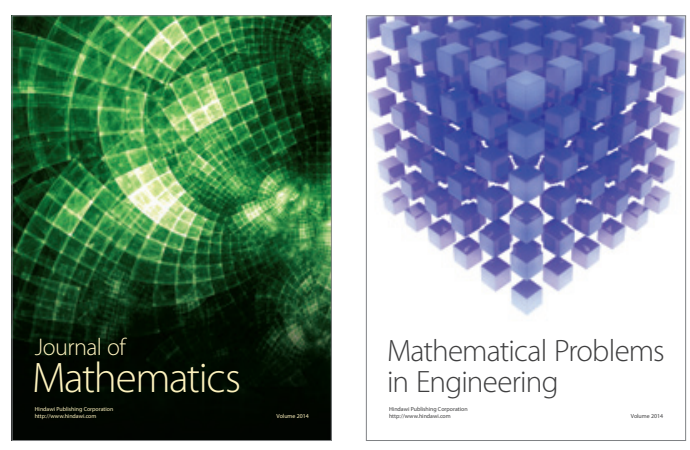

Mathematical Problems in Engineering
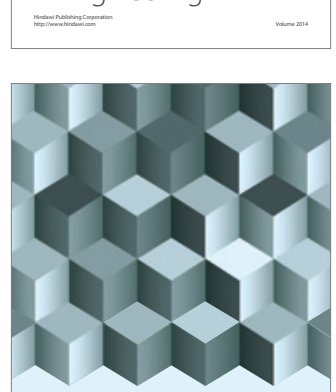

Journal of

Function Spaces
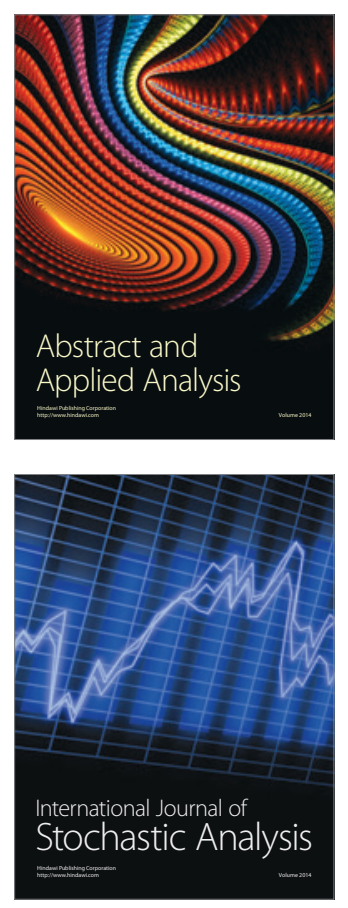

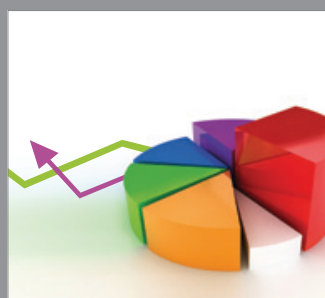

ournal of

Probability and Statistics

Promensencen
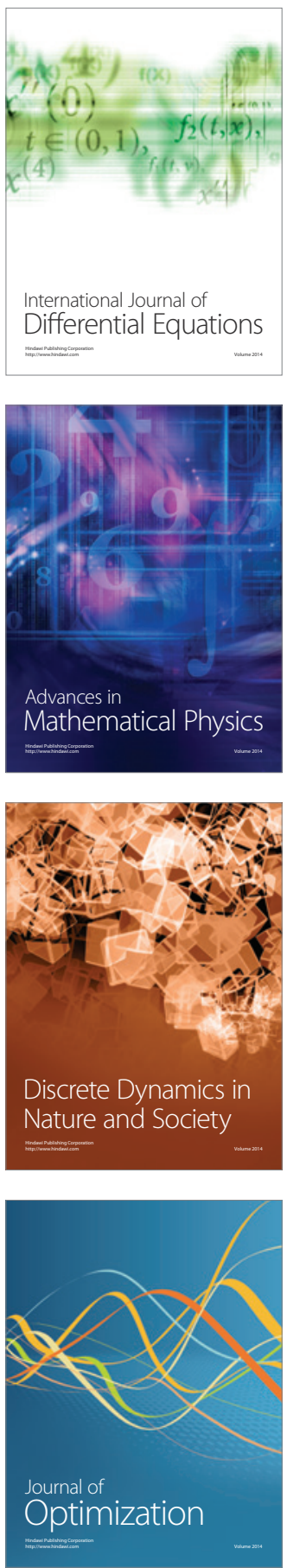